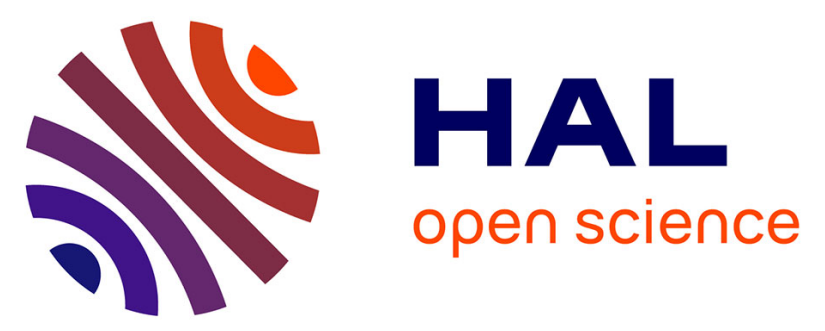

\title{
Low Volume and Label-Free Molecules Characterization and Cell Monitoring with Microwave Dielectric Spectroscopy
}

Katia Grenier, Amar Tamra, Amel Zedek, Guillaume Poiroux, François Artis, Tong Chen, Wenli Chen, M Poupot, J-J Fournié, David Dubuc

\section{To cite this version:}

Katia Grenier, Amar Tamra, Amel Zedek, Guillaume Poiroux, François Artis, et al.. Low Volume and Label-Free Molecules Characterization and Cell Monitoring with Microwave Dielectric Spectroscopy. IEEE International Microwave Bio Conference (IMBioC 2018), Jun 2018, Philadelphie, PA, United States. 3p., 10.1109/IMBIOC.2018.8428873 . hal-01951457

\author{
HAL Id: hal-01951457 \\ https://hal.laas.fr/hal-01951457
}

Submitted on 11 Dec 2018

HAL is a multi-disciplinary open access archive for the deposit and dissemination of scientific research documents, whether they are published or not. The documents may come from teaching and research institutions in France or abroad, or from public or private research centers.
L'archive ouverte pluridisciplinaire HAL, est destinée au dépôt et à la diffusion de documents scientifiques de niveau recherche, publiés ou non, émanant des établissements d'enseignement et de recherche français ou étrangers, des laboratoires publics ou privés. 


\title{
Low Volume and Label-Free Molecules Characterization and Cell Monitoring with Microwave Dielectric Spectroscopy
}

\author{
K. Grenier ${ }^{1}$, A. Tamra ${ }^{1}$, A. Zedek ${ }^{1}$, G. Poiroux ${ }^{1,2}$, F. Artis ${ }^{1,2}$, T. Chen ${ }^{1}$, W. Chen ${ }^{1}$, \\ M. Poupot ${ }^{2}$, J-J. Fournié ${ }^{2}$, and D. Dubuc ${ }^{1}$ \\ 1 LAAS-CNRS, Université de Toulouse, CNRS, UPS, Toulouse, France \\ 2 INSERM-CRCT, Toulouse, France \\ grenier@1aas.fr ; dubuc@1aas.fr
}

\begin{abstract}
Microwave dielectric spectroscopy is an attractive technique for non-destructive characterization of materials. This paper focus on its development for molecular and cellular analysis using microscale sensors. It especially focuses on the possible selectivity of the technique through the characterization of biomolecules in aqueous solution, as well as on the possible monitoring of cells reactions at the single cell level. This last capability opens the door to kinetic evaluation, which is particularly interesting and important to evaluate any stimulus on cells, such as drugs, electrical signals and even the presence of other cell.

Index Terms-microwave, dielectric spectroscopy, molecules, cells.
\end{abstract}

\section{INTRODUCTION}

Microwave and millimeterwave dielectric spectroscopy is a powerful technique to perform a non-ionizing and nondestructive characterization of materials. It is already well employed for macroscale moisture content measurements in agronomy [1-2], or water detection in soils for instance.

In the case of biological and health sensing, the analyzing technique benefits from different appealing features, which have been investigated and exploited for many decades at the macroscale. Due to the development of microtechnologies suitable for microwave components as well as for fluids handling and manipulation, the microwave sensing technique may nowadays be applied to low liquid volumes and reach the analysis of the single cell.

Among the different attractive features of microwave dielectric spectroscopy, the first one is related to the dielectric relaxation phenomenon of the water molecules, which is located in the microwave range (around $20 \mathrm{GHz}$ ). These molecules are the major constituent of the living, involved in many biological processes. Additionally, the electromagnetic fields in this frequency range penetrates beyond the capacitive bilipid cytoplasmic membrane of cells and consequently opens the door to intracellular investigations. Finally, the microwave band for the dielectric spectroscopy also enables the measurements of living cells directly into their culture medium, without tremendous losses induced by the rich ionic and nutrients content of the surrounding fluid. Therefore, the development of microwave dielectric spectroscopy for the analysis of the living at the molecular and cellular levels notably is very attractive for biological researches and biomedical applications, where non-invasivity, label-free and contact-less abilities as well as in-liquid measurements constitute important leitmotivs.

Additionally, microwave dielectric spectroscopy also presents other important attractive characteristics: a certain selectivity in the dielectric signatures, as well as the possible monitoring of reactions. Both are highlighted in this paper using examples with the microwave characterization of biomolecules or with single cells, in section II and section III respectively.

\section{BiOMOLECULES CHARACTERIZATION}

To illustrate the possible selectivity of dielectric spectra, different biomolecules in aqueous solution are evaluated with microwave dielectric spectroscopy. A coplanar waveguide surmounted perpendicularly by a microfluidic channel is used for the microwave characterization, as illustrated in Fig. 1.

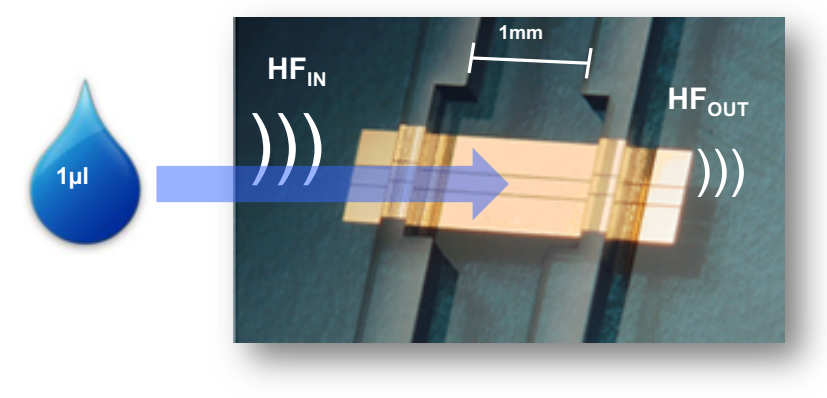

Fig. 1. Microwave sensor for permittivity characterization of liquids. The microfluidic channel requires a typical volume of 1 microliter.

The sensor only requires one microliter of liquid to be injected in the microfluidic channel, which is compatible with very low volumes of chemicals.

From $\mathrm{S}$ parameters measurements, permittivity of liquids is then extracted [3]. As the dielectric properties are dominated by the water molecules polarization in the microwave range, the permittivity variation is particularly large from $\mathrm{MHz}$ to 40 $\mathrm{GHz}$. Therefore, to enhance permittivity discrimination be- 
tween biomolecules in aqueous solution, permittivity contrasts, both for real and imaginary parts, are calculated, using equation (1), where $\varepsilon_{\text {fluid under test }}$ and $\varepsilon_{\text {ref }}$ correspond to the permittivity of the liquid under test and the permittivity of the host medium, DI water for biomolecules, respectively. It consists in subtracting the contribution of the host medium.

$$
\Delta \varepsilon=\varepsilon_{\text {fluid under test }}-\varepsilon_{\text {ref }}
$$

This protocol is applied to five amino acids: L-alanine, Llysine, L-arginine, L-thréonine and L-serine, with a concentration of 0.1 mole in aqueous solution. Corresponding results for the real part of permittivity is given in Fig. 2.

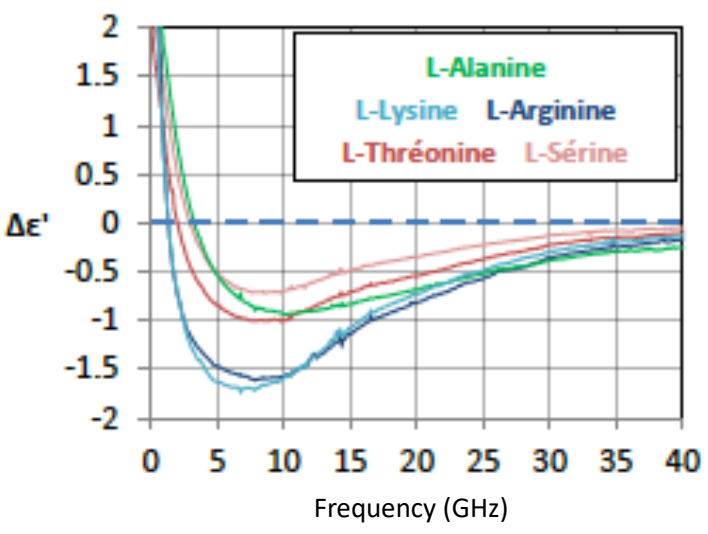

Fig. 2. Contrast of the real part of permittivity of amino acids at a concentration of $0.1 \mathrm{M}$, from $40 \mathrm{MHz}$ to $40 \mathrm{GHz}$

This figure well reflects the different dielectric properties of these amino acids. It well illustrates the possible selectivity of the sensing technique, even if it is based on a dispersion phenomenon.

\section{Microwave Cell Sensing AND Monitoring}

Microwave dielectric spectroscopy may also be applied for cell characterization. One of the key feature of the used frequency range is its compatibility with traditional cell culture medium. Fig. 3 presents the real and imaginary parts of permittivity for 3 different liquids:

- deionized water,

- a traditional culture medium: the Roswell Park Memorial Institute RPMI one, with $10 \%$ of fetal veal serum (FVS),

- and pure FVS, which is employed to provide all required nutrients to cells.

The microwave characterization of these 3 liquids indicates that their dielectric properties are quite similar and dominated by water. Moreover, the notch around $2 \mathrm{GHz}$ on $\varepsilon$ " for both FVS and culture medium is characteristic of the $9 \mathrm{~g} / 1$ salt concentration. The traditional ionic content of biological liquids does not consequently screen the dielectric behavior in the microwave range.
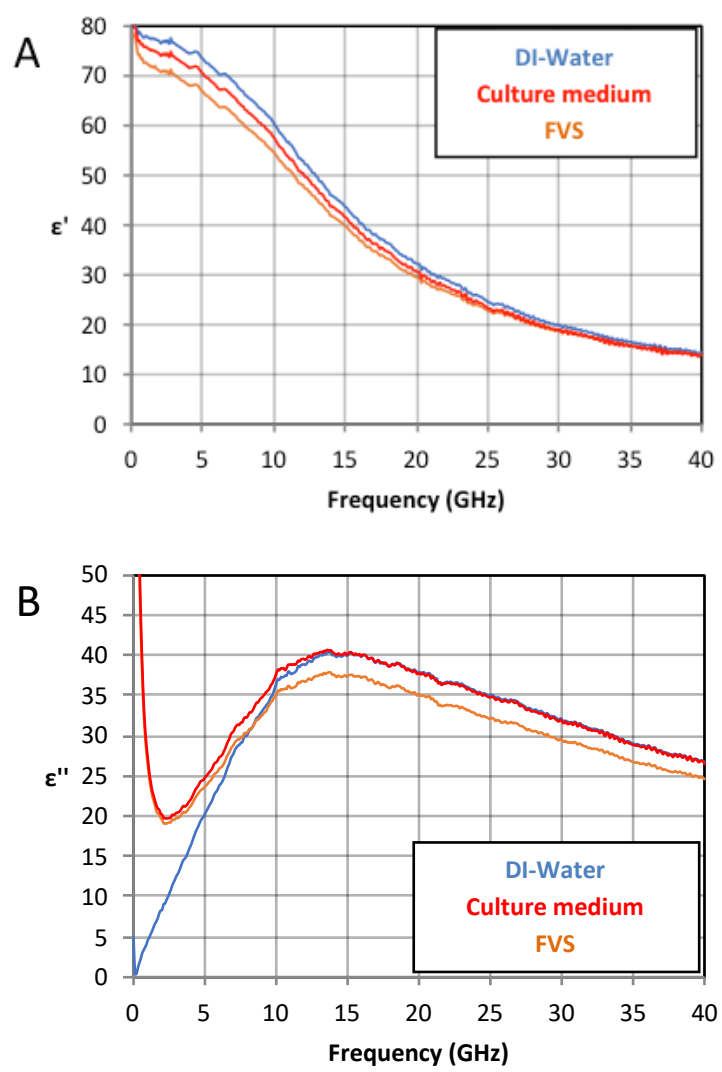

Fig. 3. A) Real and B) imaginary parts of permittivity of DI-water, culture medium with $10 \%$ of FVS and pure fetal veal serum, from $40 \mathrm{MHz}$ to $40 \mathrm{GHz}$

Subsequently, microwave dielectric spectroscopy has been demonstrated with cell suspensions [3-5], as well as at the single cell level [6-10].

Fig. 4 presents a photography of one type of sensor used for microwave characterization of single cells, which may be maintained in their culture medium [6], [8]. A hydrodynamic trap is used to block the individual cell in the center of a capacitive gap, placed in the middle of a coplanar waveguide. A cell is trapped once it arrives in front of the mechanical blocker, while all other cells are deviated. Fig. 4 presents the sensor loaded with one unique cancer cell in its culture medium, RPMI with $10 \%$ of FVS.

Such a trap configuration is appropriate to monitor in real time dielectric cell modification induced by microenvironment changes.

As an example, the chemo-induced death of an RL lymphoma cell may be followed in direct through the evaluation of the capacitive and conductive contrasts (see [11] for more details about the definition of these contrasts and extraction). After validating the stability of microwave signals of the living cells for 10 minutes, a quantity of $2 \%$ of methanol is added to the culture medium, while the cell is trapped, by simply changing the liquid environment within the microfluidic channel. In Fig. 5, the capacitive contrast versus frequency of the living cell is given in red, whereas the dielectric contrasts after 
the inception of methanol infusion is indicated with grey color after 1, 3, 5 and 15 minutes of exposure to the chemical.

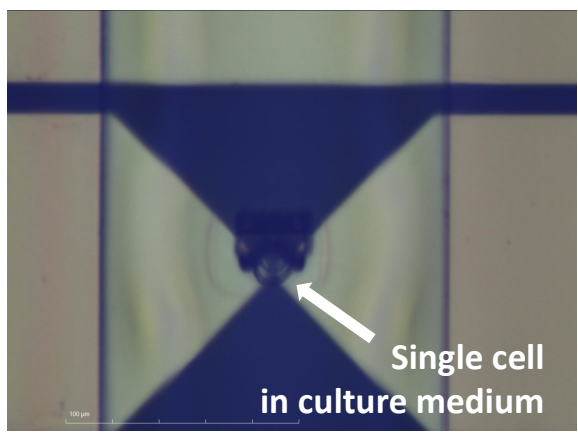

Fig. 4. Photography of the single cell microwave sensor loaded with one individual trapped cell on top of the capacitive gap for microwave characterization

Methanol induces holes in the cytoplasmic membrane, leading to an artificial and rapid cell death. The capacitive contrast spectrum obtained after 15 minutes of methanol exposure is representative of individual dead cells [12] with a low capacitive contrast between the intracellular medium and the extracellular one. Due to holes in the membrane, exchange between these two media happens and progressively lead to an equilibrium, which may be easily quantified with the monitoring of the capacitive contrast. Kinetic of cell reaction may consequently be reached with this sensing without any label, at the single cell level, and without transforming the cellular microenvironment.

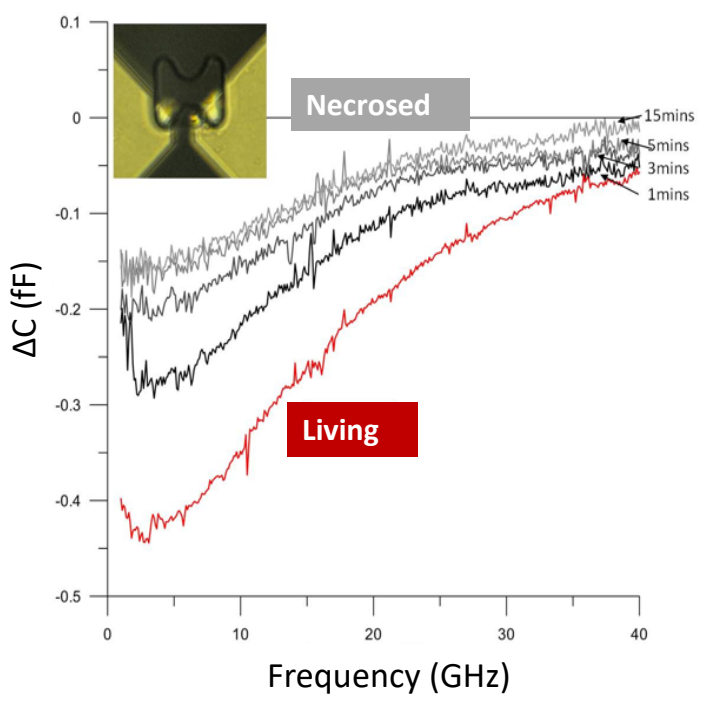

Fig. 5. Capacitive contrast variation versus time of a single RF lymphoma cell in its culture medium and then submitted to $2 \%$ of methanol

\section{CONCLUSIONS}

This paper not only illustrates the selectivity of the sensing technique with biomolecules microwave characterization. It also demonstrates the possible dielectric monitoring of individual cells, with all the advantages given by the microwave range characterization, as to say label-free, with cells directly evaluated into their culture medium. This major feature of microwave dielectric spectroscopy makes this technique particularly suitable for the non-invasive and non-destructive analysis of cells.

\section{ACKNOWLEDGMENT}

This work was partly supported by the French RENATECH network

\section{REFERENCES}

[1] S. Trabelsi et al., "New calibration technique for microwave moisture sensors," IEEE T-Inst. And Meas. 2001, 50, 4, 877-881.

[2] S. Trabelsi et al., "Influence of nonequilibrated water on microwave dielectric properties of wheat and related errors in moisture sensing," IEEE T-Inst. And Meas. 2007, 56, 1, 194-198.

[3] K. Grenier, D. Dubuc, P-E. Poleni, M. Kumemura, H. Toshiyoshi, T. Fujii, H. Fujita, 'Integrated Broadband Microwave and Microfluidic Sensor dedicated to Bioengineering', IEEE Trans. on Microwave Theory and Techniques, Vol. 57, n²12, Dec. 2009, pp. 3246-3253.

[4] K. Grenier, D. Dubuc, T. Chen, F. Artis, T. Chrétiennot, M. Poupot, JJ. Fournié, "Recent Advances in Microwave-based Dielectric Spectroscopy at the Cellular Level for Cancer Investigations," IEEE T-MTT, Vol. 61, Issue 5, Part 2, 2013, pp. 2023-2030.

[5] N. Meyne, G. Fuge, H.K. Trieu, A-P. Zeng, A.F. Jacob., Miniaturized Transmission-Line Sensor for Broadband Dielectric Characterization of Biological Liquids and Cell Suspensions. IEEE Trans. on Microwave Theory and Techniques, Vol. 63, n¹0, 2015, pp. 3026-3033.

[6] T. Chen, F. Artis, D. Dubuc, J. J. Fournié, M. Poupot, and K. Grenier, "Microwave biosensor dedicated to the dielectric spectroscopy of a single alive biological cell in its culture medium," in 2013 IEEE MTT-S International Microwave Symposium Digest (MTT), Jun 2013, pp. 1-4.

[7] Y. Ning, C. Multari, X. Luo, C. Palego, X. Cheng, J. Hwang, A. Denzi, C. Merla, F. Apollonio, M. Liberti, Broadband electrical detection of individual biological cells, IEEE T-MTT, Vol. 62, n 9, pp. 1905-1911, 2014.

[8] A. Tamra, M.-P. Rols, D. Dubuc, K. Grenier. "Microwave Monitoring of Single Cell Monocytes Subjected to Electroporation," IEEE T-MTT, 2017, DOI: 10.1109/TMTT.2017.2653776.

[9] N. Meyne, G. Fuge, A-P. Zeng, A. Jacob "Resonant Microwave Sensors for Picoliter Liquid Characterization and Non-Destructive Detection of Single Biological Cells, IEEE JERM, 2017, pp. 1-8.

[10] Y. Yang, Z. Hanqiao, Z. Junjie, W, Gaoyan, T. Tzuen-Rong, X. Xiangchun, H. Kama, and W. Pingshan "Distinguishing the viability of a single yeast cell with an ultra-sensitive radio frequency sensor," Lab.on a Chip, 2010, pp. 553-555.

[11] T. Chen, et al. «Accurate Nanoliter Liquid Characterization Up to 40 $\mathrm{GHz}$ for Biomedical Applications: Toward Noninvasive Living Cells Monitoring», IEEE T-MTT., vol. 60, n 12, p. 4171-4177, dec. 2012.

[12] A. Zedek, D. Dubuc, K. Grenier, "Microwave permittivity extraction of individual biological cells submitted to different stimuli," IEEE International Microwave Symposium Digest 2016, Hawaii, USA, 4-9 June 2017 